\title{
Epilepsy mistaken for panic attacks in an adolescent girl
}

\author{
J D D Laidlaw, Khin-Maung-Zaw
}

Complex partial seizures may present as psychiatric disorders. Family history of epilepsy and predisposing factors should be investigated
Department of Child and Adolescent Psychiatry, Gloucestershire Royal Hospital, Gloucester GL1 3NN

J D D Laidlaw, senior house officer

Khin-Maung-Zaw, consultant psychiatrist

Correspondence to: Dr K M Zaw.

BMF 1993;306:709-10
Complex partial seizures are a form of focal epilepsy associated with impairment of consciousness. The clinical presentation of such seizures is diverse, which can lead to misdiagnosis. We describe the case of a 17 year old woman who was referred to our service for treatment of panic attacks.

\section{Case report}

The girl was referred to our department with a two year history of panic attacks. She complained of recurrent episodes of acute anxiety accompanied by palpitations, hyperventilation, fuzziness in the head, butterflies in the stomach, tightness in the chest, nausea, urgency to micturate, and a choking sensation. During these attacks she would scream and run about in an agitated state. The attacks were short and occasionally occurred at night (she woke up before the attacks started). She was described as being "distant" during the attacks but said that she was aware of her actions. She would quickly come round when held still. She also mentioned outbursts of anger and physical violence, including assaulting a bystander and putting her hand through a window. The precipitants to these outbursts were trivial and she was alarmed at both the extent of her anger and her lack of control over it. She was taking a contraceptive pill and denied misusing drugs. The mental state examination and a physical examination showed no abnormality.

Between the ages of 2 and 5 she had had episodes of disturbed behaviour during sleep. A paediatrician had diagnosed these as night terrors. She was first referred to our department aged 14 years, when she had behavioural problems at school, short bouts of deep depression, and outbursts of temper. She was counselled by an educational psychologist and her condition rapidly improved. She was referred again a year later with similar problems. Her threshold for anger and frustration was low and she had once slashed her wrist. She failed to attend follow up and was discharged. There was a family history of generalised anxiety (father) and epilepsy (paternal grandmother and paternal aunt).

We were concerned that some of the features of her panic attacks were atypical, particularly the short duration, prominent motor activity, and nocturnal occurrence. These coupled with the family history of epilepsy prompted us to investigate with electroencephalography. Immediately before the recording she had an attack during which she appeared anguished and flushed, cried out in panic, and leapt off the bed. After this she was drowsy but cooperative. The electroencephalogram showed a postictal delta focus in the right frontotemporal region. Ambulatory electroencephalographic monitoring over 48 hours showed two similar attacks lasting about 40 seconds, each of which corresponded to episodes of panic. In addition a 25 second burst of delta activity was seen that did not cause panic or disturbed behaviour. Complex partial seizures were diagnosed. All blood tests and computerised tomography of her head gave normal results. She was started on carbamazepine. Her panic attacks stopped and the frequency and intensity of her rage attacks decreased.

\section{Discussion}

The prevalence of epilepsy in the general population is estimated at 4-10/1000. ${ }^{\prime}$ Complex partial seizures are a common type of epilepsy, constituting about $60 \%$ of all cases when seizures that become secondarily generalised are included. ${ }^{2}$ Complex partial seizures usually arise from the temporal lobe, but up to $30 \%$ may arise from other sites, in particular the frontal lobe. ${ }^{3}$

The clinical presentation of complex partial seizures is diverse and includes psychiatric, motor, and somatic signs and symptoms. Temporal lobe seizures produce complex auditory, visual, gustatory, and olfactory hallucinations; déjà and jamais vu; depersonalisation and derealisation; affective changes (fear, depression, euphoria); memory flashbacks; and visceral sensations (nausea, epigastric discomfort). Frontal lobe seizures show prominent motor manifestations. Occipital lobe seizures cause simple visual phenomena (sparks and flashes). Those from the parietal lobe are associated with motor and sensory symptoms and disorders of the body image.

The psychiatric symptoms of complex partial seizures are said to be indistinguishable from those of true psychiatric disorders. ${ }^{4}$ They are not limited to ictal episodes and can also occur peri-ictally and interictally. ${ }^{5}$ Lindsay et al reported that $36 \%$ of children with complex partial seizures had interictal rage attacks. ${ }^{6}$

Factors that predispose to epilepsy-for example, birth asphyxia, head injury-can help distinguish psychiatric illness from complex partial seizures. About $30 \%$ of patients with complex partial seizures have a family history of epilepsy. ${ }^{7}$ Behaviour in patients with complex partial seizures is usually more repetitive and stereotyped than in psychiatric illness. ${ }^{8}$ Messner describes abrupt recurrences, rapid shifts of symptoms, and hallucinations in relatively untroubled personalities as supportive of complex partial seizures. ${ }^{9}$ Disturbed behaviour in sleep ${ }^{10}$ and rage attacks should also raise the possibility of epilepsy. The presence of postictal confusion is also helpful.

Fear is the commonest change in mood associated with complex partial seizures ${ }^{11}$ and is thought to be exclusively related to the right temporal lobe. ${ }^{12}$ It is therefore unsurprising that such seizures are sometimes confused with panic attacks. In both conditions the fear is qualitatively different from normal anxiety, has sudden onset, and occurs without warning and for no apparent reason. However, in panic attacks the fear lasts for many minutes compared with only seconds or minutes in complex partial seizures (unless status develops).

If complex partial seizures are suspected the patient should have electroencephalography. However, although epileptiform tracings can support a diagnosis, they are not detected in all epileptic patients. A single waking interictal electroencephalogram will show epileptiform activity in about $50 \%$ of patients with epilepsy. Detection rates increase to $80 \%$ with sleep electroencephalography and to $90 \%$ with repeated recordings and videotelemetry. ${ }^{12}$ In difficult cases ambulatory electroencephalography and special electrodes may be helpful. ${ }^{13}$ 
1 Zielinski JJ. Epidemiology. In: Laidlaw J, Richens A, Oxley J, eds. A textbook of epilepsy. 3rd ed. Edinburgh: Churchill Livingstone, 1988:21-48.

2 Juul-Jensen P, Foldsprang A. Natural history of epileptic seizures. Epilepsic 1983;24:297-312.

3 Williamson PD, Spencer SS. Clinical and EEG features of complex partial seizures of extra-temporal origin. Epilepsia 1986;27(suppl 2):546-63.

Gibbs FA. Ictal and non-ictal psychiatric disorders in temporal lobe epilepsy. 7 Nerv Ment Dis 1951;113:522-8.

5 Toone BK. The psychoses of epilepsy. F R Soc Med 1991;84:457-9.

6 Lindsay J, Ounsted C, Peronelle R. Long-term outcomes in children with tindsay J, Ounsted C, Peronelle R. Long-term outcomes in children with
temporal lobe seizures. III. Psychiatric aspects in childhood and adult life. Dev Med Child Neurol 1979;21:630-9.

7 Bray PF, Wilder WC. The relation of focal to diffuse epileptiform EEG discharges in genetic epilepsy. Arch Neurol 1965;13:233-7.

8 Glassman JN, Dryer D, McCartney JR. Complex partial status epilepticus
61-4.

Messner E Covert complex partial seizures in psychotherapy. $A m$ Orthopsychiatry 1986;56:323-6.

10 Stores G. Confusions concerning sleep disorders and the epilepsies in children and adolescents. Br J Psychiatry 1991;158:1-7.

11 Fenton GW. Neuropsychiatry of epilepsy. Current Opinion In Psychiatry 1992;5:88-91.

12 Travers RF. Limbic epilepsy. $7 R$ Soc Med 1991;84:454-6.

13 Remick RA, Wada JA, Miles JE. Neuropsychiatric and electroencephalographic aspects in the diagnosis of complex partial seizures. Can $\mathcal{F}$ Psychiatry 1981;26:49-52.

(Accepted 16 December 1992)

\title{
Countdown to Community Care
}

\section{Hunting the gowk?-psychiatric community care in Scotland}

\author{
Ian Pullen
}

This is one of a series of articles looking at the forthcoming changes to community care.
Royal Edinburgh Hospital, Edinburgh EH10 5HF

Ian Pullen, consultant

psychiatrist

BMJ 1993;306:710-2
The implementation of the community care changes throughout the United Kingdom from 1 April will mark the culmination of a series of major health and social care reforms. The avowed aims of achieving value for money and improved consumer choice through the introduction of competitive internal markets have yet to be tested. The political complexion of Scotland means that any proposed change to the NHS has tended to be greeted with a mixture of suspicion and resistance. As a result very few self governing trusts and fundholding general practices exist north of the border. And although Scotland has not had a wide reaching policy of moving psychiatric patients out of hospitals, community care for mentally ill people has advanced spontaneously.

Last October Lord Fraser of Carmyllie, minister of state for health and social work at the Scottish Office, announced what was described as "the last of the major building blocks for full implementation of the government's community care policy"'-the finance for provision of community care by local authorities in the coming year. A total of $£ 41 \mathrm{~m}$ will be transferred from central government to Scottish local authorities in 1993-4 with a further $£ 20 \mathrm{~m}$ towards implementing assessment and care management. The Mental Illness Specific Grant, which had a tiny budget before 1991, will be increased to $£ 21 \mathrm{~m}$.

From the psychiatrist's perspective it is important to remember that these sums are "in support of not only the elderly, mentally ill, mentally handicapped and physically disabled people but also drug and alcohol abusers, homeless persons . . . mothers and babies in registered specialised accommodation, terminally ill people in nursing homes, people on probation and exoffenders in registered accommodation." The sums of money are large, but so too is the level of need in Scotland.

Scotland has a population of approximately 5 million, most of whom live in or close to cities or towns. An important minority of the population lives in far flung, sparsely populated areas such as the highlands and islands. The provision of psychiatric care to these areas must, necessarily, be different from that for densely populated cities. In rural areas community psychiatric nurses are more autonomous than their urban counterparts and all psychiatric staff have to travel to see patients. This diversity of service presents particular challenges for planning.

Most people with mental illness are treated in the community by general practitioners. But in Scotland, as elsewhere, most of the mental health budget has been consumed by services based at mental hospitals.
In recent years psychiatrists in Scotland have peered over the border, somewhat bemused by the speed at which psychiatric long stay beds have been emptied in England. Visiting speakers from England have chided their Scottish colleagues for their slow pace of change, citing bed numbers in Scotland and the building of an entirely new psychiatric hospital in Aberdeen as examples of outmoded practice. In fact such simplistic comparisons are misleading.

Caution is needed when attempting to interpret cross national data on psychiatric hospitals because of many confounding factors, demographic and geographical, as well as the pattern and availability of alternative services. Over the past two decades the resident population in Scottish mental hospitals fell by $20 \%{ }^{2}$ but the proportion of residents aged 65 or over rose from $45 \%$ in 1970 to $66 \%$ by $1988 .{ }^{3}$ The number of old and very old people in Scottish psychiatric hospitals accounts for much of the difference in bed numbers on the two sides of the border and reflects the poor provision of local authority run places for elderly confused people in Scotland. For example, in 1985 only 238 places in local authority and registered nursing homes for mentally ill people were recorded in national statistics in Scotland, a shortfall of 1000 places from the number recommended by the government's guidelines. ${ }^{4}$

\section{History of Scottish community care}

Despite such criticisms, Scottish mental health services have often been in the vanguard of community care developments, with services evolving locally for pragmatic reasons. But many of these services have not been evaluated effectively. At Dingleton Hospital in the borders a community model based on teams for home visiting and treatment has been used for the scattered population of 100000 since the 1960 s when Dr Maxwell Jones extended from the hospital his ideas about therapeutic communities. ${ }^{56}$ Dingleton's practice of seeing all patients in their own homes (or occasionally the general practitioner's surgery) has never been systematically evaluated. Yet this continuing service predates the better known crisis team at Napsbury Hospital, St Albans, by at least eight years.

Scotland has also led the way in moving psychiatrists into primary care. Exactly 40 years ago the first general practice health centre in Scotland was opened at Sighthill in Edinburgh. Three years later the first psychiatric clinics were held at Sighthill. ${ }^{7}$ By 1987 more than half of Scottish consultant psychiatrists were spending some time each week in primary care settings ${ }^{8}$ compared with fewer than a fifth in England 